\title{
The Retrospective Analysis of Prognostic Significance of Smoking Status in Bladder Cancer
}

\author{
Sung Han Kim${ }^{1}$, Sohee $\mathrm{Kim}^{2}$, Yoon Seok Suh${ }^{1}$, Jung Kwon Kim, Jae Young Joung', \\ Jinsoo Chung ${ }^{1}$, Weon Seo Park', Kang Hyun Lee ${ }^{1}$, Ho Kyung Seo ${ }^{1}$ \\ ${ }^{1}$ Center for Prostate Cancer, National Cancer Center, Goyang, Korea \\ ${ }^{2}$ Department of Biometric Research, National Cancer Center, Goyang, Korea
}

\begin{abstract}
Purpose: This study aimed to evaluate the prognostic significance of smoking status in muscle invasive bladder cancer (MIBC) and non-MIBC in recurrence-free (RFS), progression-free (PFS), disease-free survival (DFS), and cancer-specific survival (CSS).

Materials and Methods: We retrospectively evaluated 541 patients with MIBC and non-MIBC who were surgically treated during 2002-2013. Smoking status was defined as never smokers (NS; $n=160,30 \%$ ), former smokers (FS; smoking cessation for $\geq 1$ year, $n=176,33 \%$ ), and current smokers (CS; $>100$ cigarettes, $n=198,37 \%$ ). We statistically compared these groups' clinicopathological factors for the predictive factors for RFS and PFS for non-MIBC (NMIBC) and DFS for MIBC, and CSS using multivariate model.

Results: The CS, FS, and NS groups exhibited insignificantly different pathological staging, grades, and immunohistological characteristics $(p>0.05)$. Among the 441 patients with NMIBC, pathologic tumor size was a significant risk factor for RFS (1-3 cm: hazard ratio [HR], 1.88; $>3 \mathrm{~cm}$ : HR, 2.21; $p<0.05)$; age (HR, 1.06), intravesical therapy (HR, 0.25), and high-grade cancer (HR, 8.33) significant for PFS; and age (HR, 1.08), intravesical instillation (HR, 0.26), and smoking status (FS: HR, 0.40; CS: HR, 0.44) significant for CSS $(p<0.05)$. The 93 patients with MIBC had no significant risk factors for DFS, although their significant risk factors for CSS were age (HR, 1.05), female sex (HR, 2.64), and carcinoma in situ $(H R, 4.72)(p<0.05)$.

Conclusions: Smoking status only significantly affected CSS in patients with NMIBC. (Korean J Urol Oncol 2017;15:111-120)
\end{abstract}

Key Words: Bladder cancer $\cdot$ Muscles $\cdot$ Invasiveness $\cdot$ Smoking $\cdot$ Prognosis

\section{INTRODUCTION}

Cigarette smoking is a strong risk factor for the development of bladder cancer (BC). For example, smoking accounts for ap-

Received August 21, 2017, Revised September 25, 2017,

Accepted October 18, 2017

Corresponding Author: Ho Kyung Seo

Center for Prostate Cancer, National Cancer Center, 323 Ilsan-ro, Ilsandong-gu, Goyang 10408, Korea

E-mail: seohk@ncc.re.kr

Tel: +82-31-920-1676, Fax: +82-31-920-1790

ORCID code: https://orcid.org/0000-0003-2601-1093

- This work was supported by National Cancer Center Grant (NCC1410551). proximately one-half of the $\mathrm{BC}$ risk among men and one-third of this risk among women, and smokers have a $2-4$ fold higher risk of developing $\mathrm{BC}$, compared to nonsmokers. ${ }^{1,2}$ However, there are limited and unclear data regarding the smoking-related mechanism of carcinogenesis for BC. Furthermore, there are limited data regarding the effects of smoking on pathological staging, grading, treatment response, and prognosis among patients with BC.

Several studies have reported that smoking is associated with more invasiveness, more advanced stage and grade, higher recurrence and progression rates, shorter cancer-specific survival, and poorer therapeutic response among patients with $\mathrm{BC}^{2-7}$

(i) (8) This is an Open Access article distributed under the terms of the Creative Commons Attribution Non-Commercial License (http://creativecommons.org/licenses/by-nc/4.0/) which permits unrestricted non-commercial use, distribution, and reproduction in any medium, provided the original work is properly cited.

2017 (C) Copyright The Korean Urological Oncology Society and The Korean Prostate Society. All Rights Reserved. 
Furthermore, smoking is a prognostic factor for clinical outcomes from $\mathrm{BC}$ after transurethral resection of the bladder (TURB) and radical cystectomy (RC). ${ }^{5,8-10}$ However, other studies have reported conflicting effects of smoking on these previously confirmed prognostic effects that low-graded tumors were associated with the smoking. ${ }^{11-13}$ Therefore, the present study was designed to evaluate the prognostic significance of smoking status among clinicopathological, immunohistochemical in muscle invasive (MIBC) and nonmuscle invasive BC (NMIBC) treated with surgery. Furthermore, the effect of smoking status on postsurgical outcomes and the expression of biomarkers in the $\mathrm{BC}$ tissues were also analyzed statistically.

\section{MATERIALS AND METHODS}

\section{Ethical Considerations}

This study was approved by the Institutional Review Board (IRB) of the National Cancer Center (approval number: NCC-NCS-13-833), and conducted according to the principles expressed in the Declaration of Helsinki. The requirement for written informed consent by participant was waived, due to the retrospective design by the IRB. All patients' records/information was anonymized and deidentified prior to analysis.

\section{Patient Population}

We evaluated 541 patients with initially diagnosed $\mathrm{BC}$ who underwent TURB or RC with urinary diversion at the National Cancer Center (Goyang, Korea) during 2002-2013. The patients' clinicopathological characteristics were analyzed including smoking status (history, duration, and intensity) and the immunohistochemical expression of $\mathrm{p} 53$, retinoblastoma tumor suppressor (Rb), Bcl-2, phosphatase and tensin homolog (PTEN), and Ki-67. All pathology slides were retrospectively reviewed by a 15-year-old experienced senior genitourinary pathologist (WSP), who assigned the pathological stages and grades according to the World Health Organization's 1973 grading system and the American Joint Committee on Cancer's 2002 staging system. ${ }^{14,15}$

\section{Smoking Assessment}

At the initial clinical visit, patients consulted with a trained nurse (SJJ) and physician (HKS), who recorded self-reported data regarding cigarette smoking status (never smokers [NS], former smokers $[\mathrm{FS}],{ }^{16}$ and current smokers $[\mathrm{CS}]^{17}$ ) and the du- ration and intensity of the smoking habit, which included the number of cigarette pack-years, the number of years of smoking, and the number of years since smoking cessation. The exposure variable was defined as pack-years, which was calculated as (cigarettes smoked per day/20) $\times$ (years smoked). The NS, FS, and CS groups were defined as patients who had never smoked or who had smoked $<100$ cigarettes during their lifetime, patients who quit smoking $\geq 1$ year before their diagnosis, and patients who still smoked regularly ( $>100$ cigarettes) at the time of diagnosis, respectively. However, no information regarding smoking style, product brand, and degree of inhalation were obtained.

\section{TURB and Intravesical Instillation Therapy}

All patients with proven primary urothelial carcinoma of the bladder underwent complete TURB according to guideline's recommendations. ${ }^{18,19}$ Patients without sufficient tissue or high graded $\mathrm{BC}$ to confirm the presence of MIBC repeatedly and routinely underwent TURB at the surgeons' discretion within 2-6 weeks after the initial treatment, based on the pathological and intraoperative findings. The surgeons' discretion was used to indicate early single-dose mitomycin $\mathrm{C}$ treatment and/or adjuvant treatment with Bacillus Calmette-Guérin (BCG), mitomycin $\mathrm{C}$, epirubicin, or doxorubicin intravesical instillation therapy (IVT). The analyses included all patients with pure urothelial cell carcinomas, BC with mixed histological profiles that involved squamous cell and/or glandular differentiation, and all partial cystectomies for curative purposes. However, we excluded cases with any other histological variants, MIBC with clinical lymph node positivity and/or distant metastases, nonurothelial cell carcinomas, salvage or palliative cystectomies, and no medical follow-up data after the RC.

\section{Follow-up and Subsequent Treatment}

After treatment with TURB, RC, or partial cystectomy, patients were generally followed-up according to the guideline's recommendations. ${ }^{18,19}$ In cases of TURB for NMIBC, disease recurrence was defined as the first tumor recurrence in the bladder, regardless of tumor stage, and progression was defined as any tumor recurrence at stage $\mathrm{T} 2$ or higher in the bladder. The tumor was resected when disease recurrence was detected. When disease recurrence was not detected but the urine cytology results were positive, the patients underwent bladder and prostatic urethra biopsies in addition to an upper urinary tract 
workup. In cases of RC or partial cystectomy for MIBC, recurrence was defined as local recurrence in the pelvic cavity or distant metastasis that was confirmed using imaging and biopsy (if indicated). In cases of death, the cause of death was determined by the treating physicians, by a chart review that was corroborated by the death certificate, or by the death certificate alone. Tumor recurrence in the upper urinary tract was not considered tumor recurrence, but rather as a second primary

Table 1. Baseline demographic data from 534 patients with bladder cancer

\begin{tabular}{|c|c|c|c|c|}
\hline Variable & Never smoker $(n=160)$ & Former smoker $(n=176)$ & Current smoker $(\mathrm{n}=198)$ & p-value* \\
\hline Age (yr) & $67.5(36-91)$ & $68(36-91)$ & $65(24-87)$ & 0.068 \\
\hline Sex & & & & $<0.001$ \\
\hline Male & $76(17.4)$ & $172(39.3)$ & $190(43.4)$ & \\
\hline Female & $84(87.5)$ & $4(4.2)$ & $8(8.3)$ & \\
\hline pTstage & & & & 0.301 \\
\hline Tis, Ta, T1 & $132(82.5)$ & $143(81.3)$ & $172(86.9)$ & \\
\hline Over T2 & $28(17.5)$ & $33(18.8)$ & $26(13.1)$ & \\
\hline Grade & & & & 0.247 \\
\hline G1 & $33 / 158(20.9)$ & $24 / 174(13.8)$ & 28/198 (14.1) & \\
\hline G2 & $64 / 158(40.5)$ & $81 / 174(46.6)$ & $99 / 198(50.0)$ & \\
\hline G3 & $61 / 158$ (38.6) & $69 / 174(39.7)$ & $71 / 198(35.9)$ & \\
\hline Grade (ISUP) & & & & 0.167 \\
\hline Low & $62 / 156(39.7)$ & $62 / 172(36.0)$ & $86 / 188(45.7)$ & \\
\hline High & $94 / 156(60.3)$ & $110 / 172(64.0)$ & $102 / 188(54.3)$ & \\
\hline P53 & & & & 0.922 \\
\hline Negative & $34 / 95(35.8)$ & $41 / 112$ (36.6) & $40 / 104(38.5)$ & \\
\hline Positive & $61 / 95(64.2)$ & $71 / 112(63.4)$ & $64 / 104(61.5)$ & \\
\hline $\mathrm{Rb}$ & & & & 0.584 \\
\hline Negative & $79 / 88(89.8)$ & $84 / 98(85.7)$ & $81 / 90(90.0)$ & \\
\hline Positive & $9 / 88(10.2)$ & $14 / 98(14.3)$ & 9/90 (10.0) & \\
\hline PTEN & & & & 0.117 \\
\hline Negative & $74 / 88(84.1)$ & $72 / 97(74.2)$ & 63/88 (71.6) & \\
\hline Positive & $14 / 88(15.9)$ & $25 / 97(25.8)$ & $25 / 88(28.4)$ & \\
\hline Bcl-2 & & & & 0.954 \\
\hline Negative & $84 / 96(87.5)$ & $98 / 113(86.7)$ & $89 / 101(88.1)$ & \\
\hline Positive & $12 / 96(12.5)$ & $15 / 113(13.3)$ & 12/101 (11.9) & \\
\hline Ki-67 & & & & 0.142 \\
\hline Negative & $25 / 96(26.0)$ & $28 / 142(25.0)$ & $37 / 102(36.3)$ & \\
\hline Positive & $71 / 96(74.0)$ & $84 / 142(75.0)$ & $65 / 102(63.7)$ & \\
\hline Smoking period (yr) & NA & $30(5-65)$ & $42(5-66)$ & $<0.001^{\dagger}$ \\
\hline No. of cigarettes per day & & & & $0.505^{\dagger}$ \\
\hline $1-9$ & NA & $13 / 174(7.5)$ & $24 / 197(12.2)$ & \\
\hline $10-19$ & NA & $42 / 174(24.1)$ & 47/197 (23.9) & \\
\hline $20-29$ & NA & $93 / 174(53.4)$ & 98/197 (49.7) & \\
\hline$\geq 30$ & NA & $26 / 174(14.9)$ & $28 / 197(14.2)$ & \\
\hline Smoking amount (pack year) & NA & $26(2.5-100)$ & $37\left(2.5^{-110}\right)$ & $0.002^{\dagger}$ \\
\hline Cumulative smoking exposure & & & & $<0.001^{\dagger}$ \\
\hline Light short & NA & $11 / 173(6.4)$ & $3 / 195(1.5)$ & \\
\hline Light long & NA & $44 / 173(25.4)$ & $67 / 195(34.4)$ & \\
\hline Heavy short & NA & $18 / 173(10.4)$ & $3 / 195(1.5)$ & \\
\hline Heavy long & NA & $100 / 173(57.8)$ & $122 / 195(62.6)$ & \\
\hline
\end{tabular}

Values are presented as median (range) or number (\%).

ISUP: International Society of Urologic Pathologists, Rb: retinoblastoma tumor suppressor, PTEN: phosphatase and tensin homolog, NA: not available.

${ }^{*}$ Chi-square tests and Kruskall-Wallis tests as appropriate. ${ }^{\dagger}$ Former smoker vs. current smoker. 
tumor.

\section{Immunohistochemistry and Assessment of Tissue Microarrays}

Paraffin-embedded sections of the excised tumors were subjected to immunohistochemical analysis to evaluate the expression of $\mathrm{Rb}, \mathrm{p} 53, \mathrm{Bcl}-2, \mathrm{PTEN}$, and $\mathrm{Ki}-67$. The formalin-fixed paraffin-embedded tissues were sectioned, mounted, deparaffinized, dehydrated, and stained with 5 antibodies according to the protocol from our previous study. ${ }^{20}$ The immunohistochemical results were independently evaluated by 2 blinded pathologists under a light microscope, the results were classified as positive or negative, and were subsequently cross-checked. Positive Bcl-2 expression was defined as positive staining in $>10 \%$ of the tumor cells. Tissues were considered positive for $\mathrm{p} 53$ overexpression when $>10 \%$ of the nuclei exhibited positive staining, and the cutoff for Ki-67 overexpression was $20 \%$. Loss of $\mathrm{Rb}$ was considered present when $>10 \%$ of the tissue nuclei exhibited negative staining in the presence of normal epithelial and mesenchymal cell expression.
Loss of PTEN was considered present when $>50 \%$ of the cells exhibited negative cytoplasmic staining.

\section{Statistical Analysis}

Baseline characteristics were evaluated using the chi-square test and Kruskal-Wallis test, as appropriate, according to smoking status (NS vs. FS vs. CS). RFS or DFS was calculated as the interval from surgery to the first documented clinical recurrence. PFS and CSS were measured from the date of treatment initiation to the date of $\mathrm{BC}$ progression or death. The Kaplan-Meier method, log-rank test, and a Cox proportional hazard model were used for the survival analyses. Only factors with a p-values of $<0.10$ in the univariate analyses were entered into the multivariable Cox regression model. We also excluded variables where $>20 \%$ of the patients exhibited missing data. Statistical analyses were performed using Stata software ver. 13.1 (StataCorp., College Station, TX, USA), all analyses were 2-tailed, and differences were considered statistically significant at a $\mathrm{p}$-value of $<0.05$.

Table 2. Analysis of recurrence-free survival (RFS), progression-free survival (PFS), and cancer-specific survival (CSS) in 441 patients with nonmuscle invasive bladder cancer according to smoking status

\begin{tabular}{|c|c|c|c|c|c|c|c|c|c|}
\hline \multirow{2}{*}{ Variable } & \multicolumn{3}{|c|}{ RFS $(n=286)$} & \multicolumn{3}{|c|}{ PFS $(n=296)$} & \multicolumn{3}{|c|}{ CSS $(n=304)$} \\
\hline & HR & p-value & $95 \% \mathrm{CI}$ & HR & p-value & $95 \% \mathrm{CI}$ & HR & p-value & $95 \% \mathrm{CI}$ \\
\hline Age & & & & 1.06 & 0.008 & $1.02-1.11$ & 1.08 & $<0.001$ & $1.05^{-1.12}$ \\
\hline Instillation therapy & 0.65 & 0.149 & $0.36-1.17$ & 0.25 & 0.001 & $0.11-0.59$ & 0.26 & 0.001 & $0.12-0.58$ \\
\hline \multicolumn{10}{|l|}{ Grade } \\
\hline G1 & 1.00 & & & 1.00 & & & 1.00 & & \\
\hline G2 & 1.17 & 0.632 & $0.62-2.21$ & 0.49 & 0.490 & $0.07-3.65$ & 0.75 & 0.580 & $0.28-2.05$ \\
\hline G3 & 1.53 & 0.313 & $0.67-3.51$ & 0.68 & 0.721 & $0.08-5.81$ & 1.46 & 0.560 & $0.41-5.16$ \\
\hline \multicolumn{10}{|l|}{ Grade } \\
\hline Low (ISUP) & 1.00 & & & 1.00 & & & 1.00 & & \\
\hline High & 1.03 & 0.910 & $0.62-1.72$ & 8.33 & 0.007 & $1.79-38.68$ & 1.04 & 0.937 & $0.42-2.56$ \\
\hline \multicolumn{10}{|l|}{ Tumor number } \\
\hline 1 & 1.00 & & & 1.00 & & & 1.00 & & \\
\hline $2-7$ & 0.90 & 0.701 & $0.53-1.54$ & 0.88 & 0.789 & $0.35-2.22$ & 1.02 & 0.955 & $0.44-2.37$ \\
\hline$>7$ & 1.52 & 0.170 & $0.83-2.78$ & 1.41 & 0.504 & $0.51-3.89$ & 1.59 & 0.299 & $0.66-3.83$ \\
\hline \multicolumn{10}{|l|}{ Tumor size $(\mathrm{cm})$} \\
\hline$<1$ & 1.00 & & & & & & & & \\
\hline $1-3$ & 1.88 & 0.012 & $1.15^{-3.07}$ & & & & & & \\
\hline$>3$ & 2.21 & 0.003 & $1.31-3.73$ & & & & & & \\
\hline Lymphovascular invasion & 0.89 & 0.760 & $0.44-1.82$ & 1.17 & 0.750 & $0.45-3.06$ & & & \\
\hline Never smoker & 1.00 & & & 1.00 & & & 1.00 & & \\
\hline Former smoker & 1.14 & 0.632 & $0.67-1.93$ & 0.96 & 0.928 & $0.38-2.44$ & 0.40 & 0.013 & $0.2-0.82$ \\
\hline Current smoker & 1.33 & 0.265 & $0.81-2.19$ & 1.40 & 0.491 & $0.54-3.62$ & 0.44 & 0.026 & $0.21-0.90$ \\
\hline
\end{tabular}

HR: hazard ratio, CI: confidence interval, ISUP: International Society of Urologic Pathologists. 
A

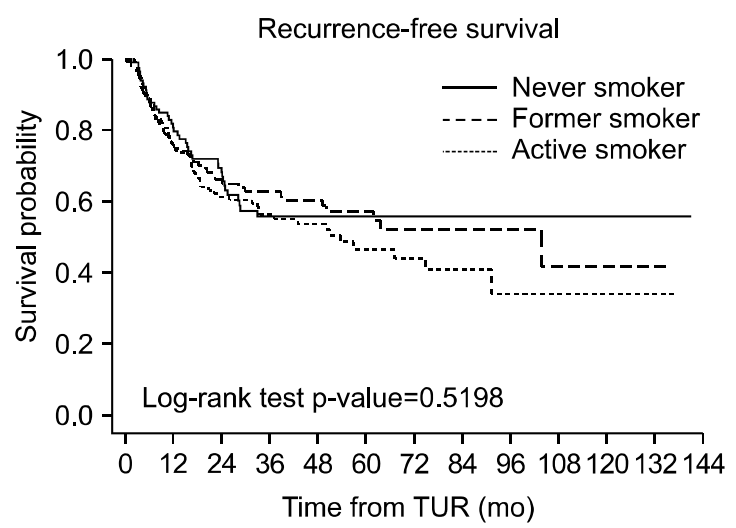

Number at risk

$\begin{array}{llllllllllllll}\text { Never smoker } & 125 & 76 & 56 & 35 & 21 & 14 & 12 & 8 & 5 & 3 & 1 & 1 & 0\end{array}$

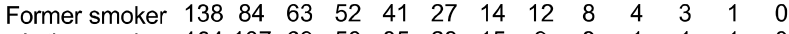

Active smoker $164 \begin{array}{llllllllllll}107 & 69 & 50 & 35 & 23 & 15 & 9 & 3 & 1 & 1 & 1 & 0\end{array}$

\section{C}

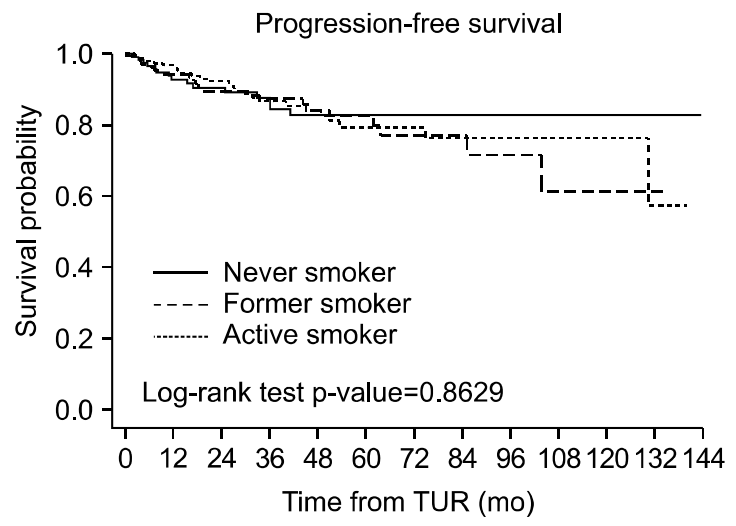

Number at risk

$\begin{array}{llllllllllllll}\text { Never smoker } & 127 & 89 & 71 & 56 & 36 & 24 & 20 & 16 & 10 & 6 & 4 & 4 & 0\end{array}$ Former smoker $140 \begin{array}{lllllllllllll}105 & 86 & 71 & 55 & 35 & 21 & 16 & 10 & 6 & 3 & 1 & 0\end{array}$

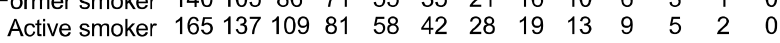

\section{E}

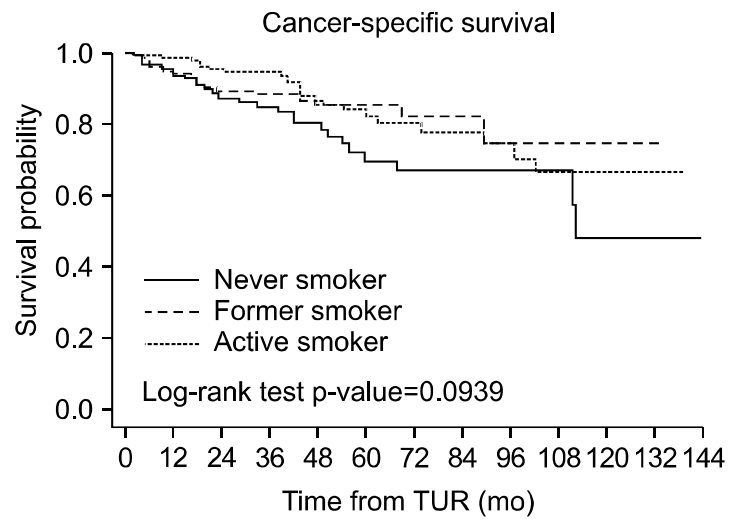

Number at risk

$\begin{array}{llllllllllllll}\text { Never smoker } & 128 & 99 & 75 & 61 & 43 & 27 & 22 & 18 & 12 & 8 & 4 & 4 & 0\end{array}$ $\begin{array}{llllllllllllll}\text { Former smoker } & 141 & 108 & 90 & 74 & 58 & 36 & 21 & 17 & 10 & 7 & 3 & 1 & 0\end{array}$

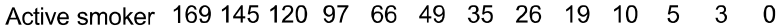

B

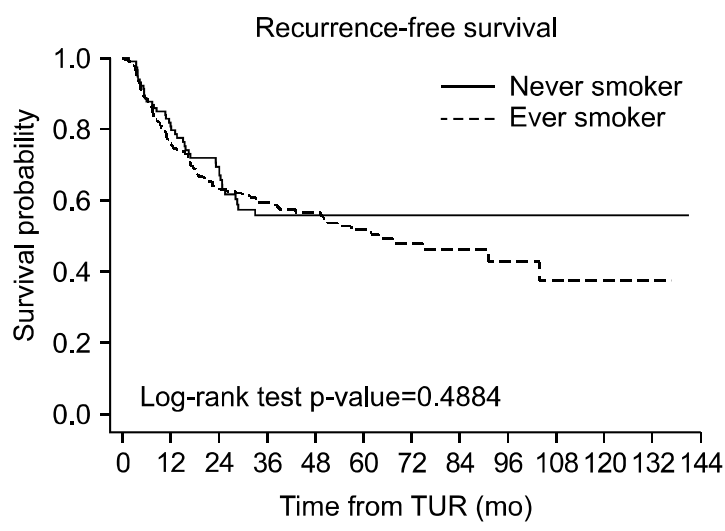

Number at risk

$\begin{array}{llllllllllllll}\text { Never smoker } & 125 & 76 & 56 & 35 & 21 & 14 & 12 & 8 & 5 & 3 & 1 & 1 & 0\end{array}$

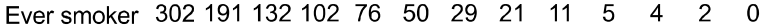

D

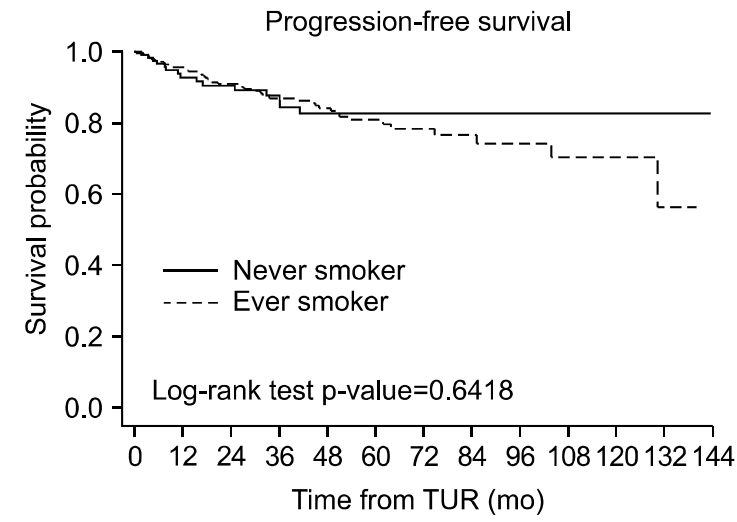

Number at risk

$\begin{array}{llllllllllllll}\text { Never smoker } & 127 & 89 & 71 & 56 & 36 & 24 & 20 & 16 & 10 & 6 & 4 & 4 & 0\end{array}$

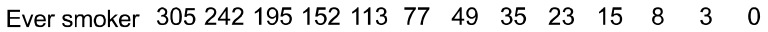

$\mathbf{F}$

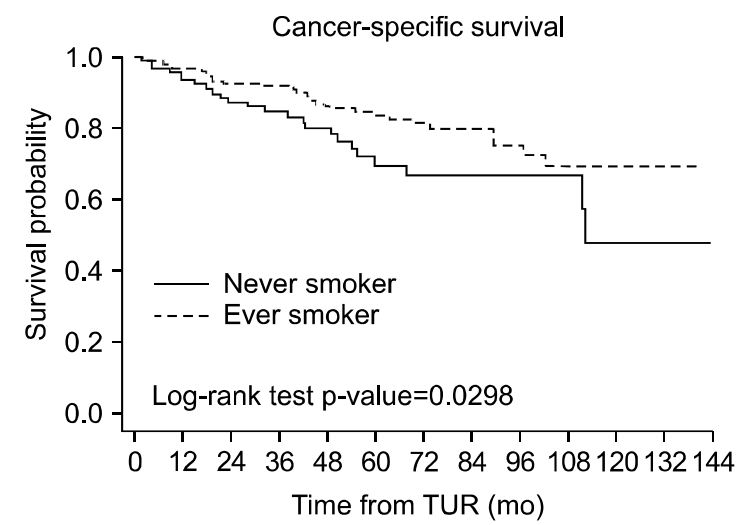

Number at risk

$\begin{array}{llllllllllllll}\text { Never smoker } & 128 & 99 & 75 & 61 & 43 & 27 & 22 & 18 & 12 & 8 & 4 & 4 & 0\end{array}$ Ever smoker $310253210171 \quad 124 \quad 85 \begin{array}{lllllllll}56 & 43 & 29 & 17 & 8 & 4 & 0\end{array}$

Fig. 1. Recurrence-free (A, B), progression-free $(\mathrm{C}, \mathrm{D})$, and cancer-specific survival $(\mathrm{E}, \mathrm{F})$ curves according the smoking status among patients with nonmuscle invasive bladder cancer. TUR: transurethral resection. 


\section{RESULTS}

Among the 534 patients, we identified 441 patients (82.6\%) with NMIBC and 93 patients (17.4\%) with MIBC patients. These patients included 160 NS (30\%), 176 FS (33\%), and 198 CS (37\%). When we compared the CS, FS, and NS groups, we did not observe any significant differences in their pathological staging, grades, and immunohistological findings (Table 1). The median smoking duration was 30 years (range, 5-65 years) for FS, and 42 years (range, 5-66 years) for CS. The smoking amounts were 26 pack-years (range, 2.5-100 pack/yr) for FS, and 37.0 pack-years (range, 2.5-110 pack-years) for CS.

Among the 441 patients with NMIBC, the significant risk factor for recurrence was pathologic tumor size $(1-3 \mathrm{~cm}$ : hazard ratio [HR], 1.88; 95\% confidence interval [CI], 1.15-3.07; >3 cm: HR, 2.21; 95\% CI, 1.31-3.73; p<0.05) (Table 2, Supplementary Table 1). The factors that were significantly associated with progression were age (HR, 1.06; 95\% CI, 1.021.11), IVT (HR, 0.25; 95\% CI, 0.11-0.59), and high-grade cancer (HR, 8.33; 95\% CI, 1.79-38.68) (all, p<0.05) (Table 2, Supplementary Table 2 ). The factors that were significantly associated with mortality were age (HR, 1.08 ; $95 \%$ CI, $1.05^{-}$ 1.12), IVT (HR, 0.26; 95\% CI, 0.12-0.58), and smoking status (FS: HR, 0.40; 95\% CI, 0.20-0.82; CS: HR, 0.44; 95\% CI, 0.21 -0.90) (all, p<0.05) (Table 2, Supplementary Table 3). The log-rank test was used to compare the Kaplan-Meier survival curves according to smoking status, and revealed that NS exhibited significantly better CSS, compared to ever smokers ( $\mathrm{p}=0.0298)$ (Fig. 1, Table 2, and Supplementary Table 4).

Among the 93 patients with MIBC, there were no significant risk factors for DFS (Table 3, Supplementary Table 5). The sig- nificant risk factors for mortality were age (HR, 1.05; 95\% CI, 1.01-1.08), female sex (HR, 2.64; 95\% CI, 1.04-6.70), and carcinoma in situ (HR, 4.72; 95\% CI, 1.50-14.86) (all, $\mathrm{p}<0.05$ ) (Table 3). The log-rank test was used to compare the Kaplan-Meier survival curves, and revealed significantly different CSS according to smoking status $(\mathrm{p}<0.05)$, although no differences were observed for DFS (Fig. 2, Table 3, Supplementary Table 6).

\section{DISCUSSION}

Cigarette smoking has known a leading cause of $\mathrm{BC}$, due to the production of multiple carcinogenic substances that can induce sequential genetic and epigenetic changes and instabilities in the urothelium. ${ }^{21,22}$ These substances are cleared via excretion through the bladder, which leads to a risk of urothelial carcinoma that increases in proportion to the duration of exposure to these carcinogens in the urine. ${ }^{23}$ A significant dose-response relationship between cumulative smoking exposure and clinical outcomes has been shown among patients with primary NMIBC. ${ }^{2,4}$ This relationship indicates that the interaction between genetic factors and smoking exposure might influence the development of more advanced and higher-grade tumors, recurrence, progression, and cancer-specific mortality due to $\mathrm{BC}^{12,21}$

However, as the characteristics of $\mathrm{BC}$ according to smoking status have not been sufficiently evaluated, this study evaluated the different prognostic effects of smoking status on BC according to muscle-invasiveness and found that only smoking status significantly affected CSS in NMIBC, but any significant differences in RFS and PFS were not observed. Previous prospective cohort study of 348,010 Korean participants inves-

Table 3. Analysis of disease-free survival (DFS) and cancer-specific survival (CSS) in 93 patients with muscle invasive bladder cancer according to smoking status

\begin{tabular}{|c|c|c|c|c|c|c|}
\hline \multirow{2}{*}{ Variable } & \multicolumn{3}{|c|}{ DFS $(n=52)$} & \multicolumn{3}{|c|}{$\operatorname{CSS}(n=92)$} \\
\hline & HR & $\mathrm{p}$-value & $95 \% \mathrm{CI}$ & HR & p-value & $95 \% \mathrm{CI}$ \\
\hline Age & - & - & - & 1.05 & 0.006 & $1.01-1.08$ \\
\hline Female sex & 9.65 & 0.07 & $0.82-113.69$ & 2.64 & 0.041 & $1.04-6.70$ \\
\hline Carcinoma in situ & - & - & - & 4.72 & 0.008 & $1.50-14.86$ \\
\hline Never smoker & 1.00 & - & - & 1.00 & - & - \\
\hline Former smoker & 4.55 & 0.229 & $0.39-53.58$ & 0.70 & 0.409 & $0.30-1.64$ \\
\hline Current smoker & 1.54 & 0.726 & $0.14-17.25$ & 0.38 & 0.058 & $0.14-1.03$ \\
\hline
\end{tabular}

HR: hazard ratio, CI: confidence interval, ISUP: International Society of Urologic Pathologists. 
A

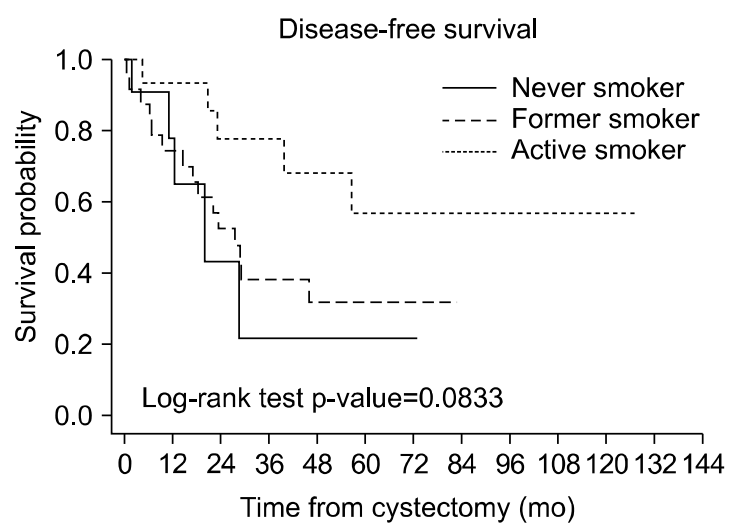

Number at risk

$\begin{array}{llllllllllllll}\text { Never smoker } & 12 & 6 & 2 & 1 & 1 & 1 & 1 & 0 & 0 & 0 & 0 & 0 & 0\end{array}$

$\begin{array}{lllllllllllllll}\text { Former smoker } & 24 & 17 & 12 & 7 & 5 & 3 & 1 & 0 & 0 & 0 & 0 & 0 & 0\end{array}$

Active smoker $16 \begin{array}{lllllllllllll}14 & 10 & 9 & 7 & 5 & 5 & 5 & 3 & 3 & 1 & 0 & 0\end{array}$

\section{C}

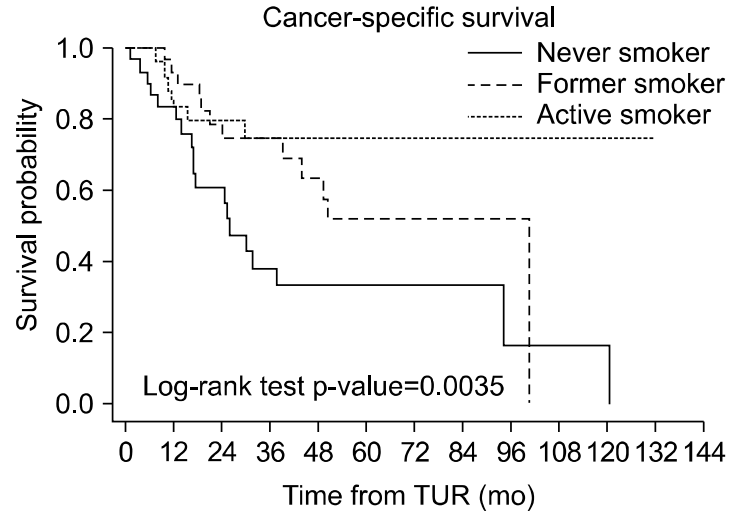

Number at risk

$\begin{array}{llllllllllllll}\text { Never smoker } & 31 & 23 & 14 & 8 & 5 & 4 & 4 & 3 & 1 & 1 & 1 & 0 & 0\end{array}$

$\begin{array}{llllllllllllll}\text { Former smoker } & 34 & 27 & 19 & 13 & 11 & 7 & 4 & 2 & 1 & 0 & 0 & 0 & 0\end{array}$

$\begin{array}{llllllllllllll}\text { Active smoker } & 28 & 20 & 15 & 13 & 10 & 8 & 7 & 7 & 5 & 5 & 2 & 0 & 0\end{array}$
B

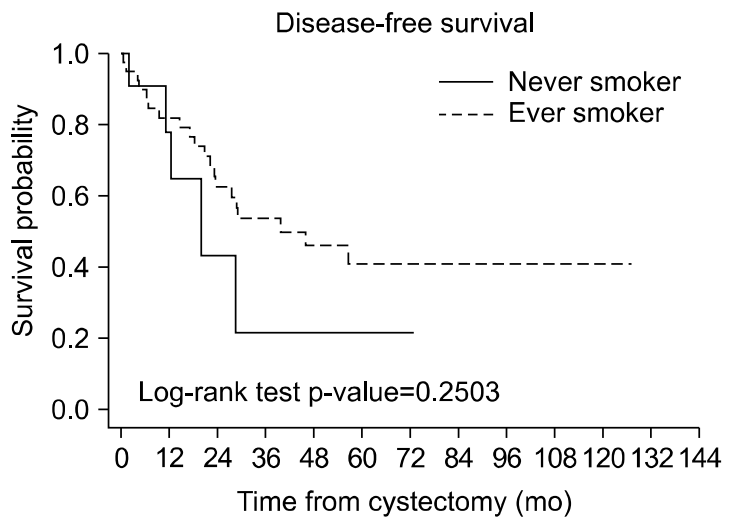

Number at risk

$\begin{array}{lccccccccccccc}\text { Never smoker } & 12 & 6 & 2 & 1 & 1 & 1 & 1 & 0 & 0 & 0 & 0 & 0 & 0\end{array}$

$\begin{array}{llllllllllllll}\text { Ever smoker } & 40 & 31 & 22 & 16 & 12 & 8 & 6 & 5 & 3 & 3 & 1 & 0 & 0\end{array}$

D

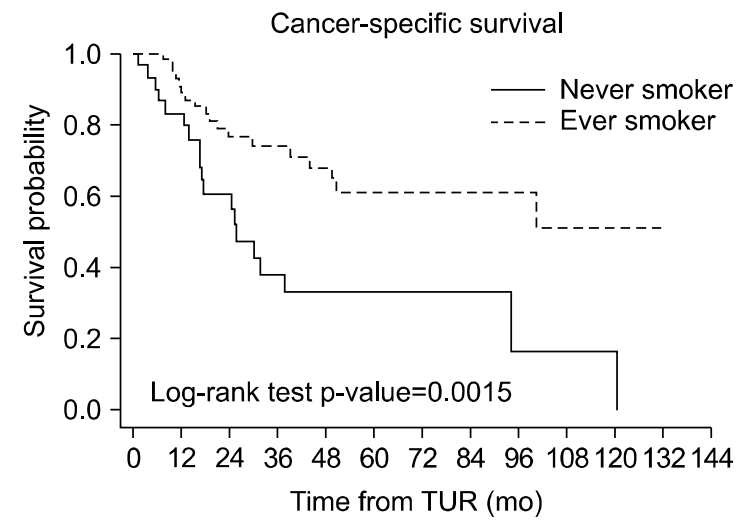

Number at risk

$\begin{array}{llllllllllllll}\text { Never smoker } & 31 & 23 & 14 & 8 & 5 & 4 & 4 & 3 & 1 & 1 & 1 & 0 & 0\end{array}$ $\begin{array}{llllllllllllll}\text { Ever smoker } & 62 & 47 & 34 & 26 & 21 & 15 & 11 & 9 & 6 & 5 & 2 & 0 & 0\end{array}$

Fig. 2. Disease-free (A, B) and cancer-specific survival (C, D) curves according to smoking status among patients with muscle invasive bladder cancer. TUR: transurethral resection.

tigated the relationship of smoking status with $\mathrm{BC}$ incidence and mortality, and found that CS exhibited a higher incidence and mortality in both sexes, although these factors were not affected by the amount and duration of smoking. ${ }^{20}$ Another Korean study of 156 patients with BC investigated the effect of smoking on RFS and PFS in BC, and found no significant differences in the stages and grades among the CS, FS, and NS. Nevertheless, the authors reported a significant difference in the recurrence rate between the FS and NS groups ( $p$ $<0.05)^{24}$

In the present study, we did not observed any differences in the aggressiveness and cancer-related immunohistochemical findings according to smoking status. Interestingly, the only significant difference according to smoking status was observed for CSS, and only smokers (CS or FS) with NMIBC exhibited improved CSS outcomes. This finding may be related to the fact that smokers are more likely to visit hospitals and undergo rigorous evaluations for cardiovascular and pulmonary disease (vs. patients who have never smoked). Thus, physicians might be more aware of $\mathrm{BC}$ in these patients, who might be diagnosed and treated at lower-grade disease (vs. nonsmokers). Another explanation might be that unidentified genetic, ethnic, environmental, behavioral, or lifestyle factors might have influence the association between smoking and $\mathrm{BC}$ prognosis, as various factors that we did not account for have been relevant in Western studies. $^{25}$

NMIBC develops from urothelial cells that have been damaged by the carcinogens from cigarette smoke. In CS or NS patients, their urothelial cells would have high levels of exposure to these carcinogens, which might lead to disease re- 
currence, progression, and biological aggressiveness, which are important end points in the management of NMIBC. ${ }^{6-8,11,12}$ However, in this study, any significant differences in RFS and PFS were observed according to smoking status, although CS exhibited a significantly improved CSS. The absence of a significant association between smoking status and RFS in NMIBC might be due to IVT obscuring any differences in recurrence or mortality, as it significantly affected PFS and CSS in this study. ${ }^{26,27}$ Some reports have also suggested that smoking affects the efficacy of IVT and BCG by reducing cytokine activity, B- and T-cell responses, and natural killer cell activation. $^{28,29}$ However, one recent study did not find that smoking affected BCG response, ${ }^{29}$ and the present study's results also indicate that the efficacy of IVT in NMIBC was independently able to prevent disease progression to MIBC.

Another reason for the insignificant association between smoking status and $\mathrm{BC}$ prognosis might be that the influence of smoking status on recurrence was more relevant among high-risk patients during a long-term follow-up. However, this study did not classify the patients into risk groups, and the median follow-up time was not only 4 years not enough long to expect the prognostic influences of smoking status in BC. Therefore, longer follow-up and classification according to risk may be necessary to detect differences in recurrence according to smoking status.

Given the hypothetical interaction between carcinogens in the urine and detrimental genetic changes throughout the urothelium, it is possible that $\mathrm{RC}$ is an important prognostic factor in patients with MIBC. In this context, RC might result in complete removal of the damaged urothelial cells and elimination of carcinogen exposure, due to the urinary diversion. Several clinical studies also support the hypothesis that smokers with $\mathrm{BC}$ experience lower rates of new tumor occurrence, and worse survival and mortality outcomes, after urinary diversion procedures. ${ }^{9}$ Another Korean study found that NS tended to have poorer RFS, although there was no association between smoking and $\mathrm{BC}$ prognosis after $\mathrm{RC},{ }^{11}$ similar to this study reporting smoking status not an independent risk factor for DFS in MIBC.

Lastly, the association between the expression of various common biomarkers (p53, Rb, PTEN, Bcl-2, and Ki-67) and disease recurrence or progression according to smoking status has been evaluated that any statistically significant associations were found in this study. In contrast, a recent study used similar biomarkers (p53, p21, pRb, and p27) found that smoking was a significant prognostic factor in $\mathrm{BC}$, and that these biomarkers predicted recurrence and mortality according to smoking status. ${ }^{30}$ This discrepancy may be related to different methodologies in these studies.

This study contained several important limitations that warrant consideration such as a nonrandomized retrospective design with relatively short follow-up, and a possible recall bias from the self-reported smoking data. Further absence of considerations were also limited factors of this study about the patients' comorbidities, smoking habits (amount, duration, and time since cessation), forms of cigarette products, the effect of different intravesical chemotherapy and BCG agents. In addition, further consideration about the risk stratification including stage and grade might be helpful to explain the relationship between the smoking and the prognoses in patients with BC. Therefore, a larger prospective study with a long-term follow-up, as well as biochemical verification of smoking and hormonal status, is needed to identify sex-related differences and compensate for these limitations.

\section{CONCLUSIONS}

In the present study, no statistically significant differences of poor prognoses were observed according to smoking status among the patients' clinicopathological and prognostic characteristics in BC. Further larger prospective study with a long-term follow-up would be needed for the prognostic effect of smoking status in BC.

\section{CONFLICT OF INTEREST}

The authors claim no conflicts of interest.

\section{SUPPLEMENTARY MATERIALS}

Supplementary Tables can be found via https://doi.org/ 10.22465/kjuo.2017.15.3.111.

\section{REFERENCES}

1. Crivelli JJ, Xylinas E, Kluth LA, Rieken M, Rink M, Shariat SF. Effect of smoking on outcomes of urothelial carcinoma: a systematic review of the literature. Eur Urol 2014;65:742-54. 
2. Zeegers MP, Tan FE, Dorant E, van Den Brandt PA. The impact of characteristics of cigarette smoking on urinary tract cancer risk: a meta-analysis of epidemiologic studies. Cancer 2000;89:630-9.

3. van Roekel EH, Cheng KK, James ND, Wallace DM, Billingham LJ, Murray PG, et al. Smoking is associated with lower age, higher grade, higher stage, and larger size of malignant bladder tumors at diagnosis. Int J Cancer 2013;133:446-54.

4. Thompson IM, Peek M, Rodriguez FR. The impact of cigarette smoking on stage, grade and number of recurrences of transitional cell carcinoma of the bladder. J Urol 1987;137: 401-3.

5. Lammers RJ, Witjes WP, Hendricksen K, Caris CT, Janzing-Pastors MH, Witjes JA. Smoking status is a risk factor for recurrence after transurethral resection of non-muscle-invasive bladder cancer. Eur Urol 2011;60:713-20.

6. Fleshner N, Garland J, Moadel A, Herr H, Ostroff J, Trambert $\mathrm{R}$, et al. Influence of smoking status on the disease-related outcomes of patients with tobacco-associated superficial transitional cell carcinoma of the bladder. Cancer 1999;86:2337-45.

7. Aveyard P, Adab P, Cheng KK, Wallace DM, Hey K, Murphy MF. Does smoking status influence the prognosis of bladder cancer? A systematic review. BJU Int 2002;90:228-39.

8. Rink M, Zabor EC, Furberg H, Xylinas E, Ehdaie B, Novara $\mathrm{G}$, et al. Impact of smoking and smoking cessation on outcomes in bladder cancer patients treated with radical cystectomy. Eur Urol 2013;64:456-64.

9. Yafi FA, Aprikian AG, Chin JL, Fradet Y, Izawa J, Estey E, et al. Contemporary outcomes of 2287 patients with bladder cancer who were treated with radical cystectomy: a Canadian multicentre experience. BJU Int 2011;108:539-45.

10. Rink M, Furberg H, Zabor EC, Xylinas E, Babjuk M, Pycha A, et al. Impact of smoking and smoking cessation on oncologic outcomes in primary non-muscle-invasive bladder cancer. Eur Urol 2013;63:724-32.

11. Lee C, Kim KH, You D, Jeong IG, Hong B, Hong JH, et al. Smoking and survival after radical cystectomy for bladder cancer. Urology 2012;80:1307-12.

12. Sturgeon SR, Hartge P, Silverman DT, Kantor AF, Linehan WM, Lynch C, et al. Associations between bladder cancer risk factors and tumor stage and grade at diagnosis. Epidemiology 1994;5:218-25.

13. Ouerhani S, Rouissi K, Marrakchi R, Riadh Ben Slama M, Sfaxi M, Ayed M, et al. Do smoking and polymorphisms in xenobiotic metabolizing enzymes affect the histological stage and grade of bladder tumors? Bull Cancer 2009;96:E23-9.

14. Edge SB, Byrd DR, Compton CC, Fritz AG, Greene FL, Trotti A, editors. AJCC cancer staging manual. 7th ed. New York: Springer; 2010.

15. May M, Brookman-Amissah S, Roigas J, Hartmann A, Störkel S, Kristiansen G, et al. Prognostic accuracy of individual uropathologists in noninvasive urinary bladder carci- noma: a multicentre study comparing the 1973 and 2004 World Health Organisation classifications. Eur Urol 2010;57: 850-8.

16. Gakis G, Efstathiou J, Lerner SP, Cookson MS, Keegan KA, Guru KA, et al. ICUD-EAU International Consultation on Bladder Cancer 2012: radical cystectomy and bladder preservation for muscle-invasive urothelial carcinoma of the bladder. Eur Urol 2013;63:45-57.

17. Stadler WM, Figlin RA, McDermott DF, Dutcher JP, Knox JJ, Miller WH Jr, et al. Safety and efficacy results of the advanced renal cell carcinoma sorafenib expanded access program in North America. Cancer 2010;116:1272-80.

18. Babjuk M, Burger M, Zigeuner R, Shariat SF, van Rhijn BW, Compérat $\mathrm{E}$, et al. EAU guidelines on non-muscle-invasive urothelial carcinoma of the bladder: update 2013. Eur Urol 2013;64:639-53.

19. Clark PE, Agarwal N, Biagioli MC, Eisenberger MA, Greenberg RE, Herr HW, et al. Bladder cancer. J Natl Compr Canc Netw 2013;11:446-75.

20. Joung JY, Yang SO, Jeong IG, Han KS, Seo HK, et al. Identification of immunohistochemical factors that predict the synchronous or metachronous development of bladder tumors in patients with upper urinary tract tumors. Urol Int 2008;81: 306-11.

21. Jiang X, Castelao JE, Yuan JM, Stern MC, Conti DV, Cortessis VK, et al. Cigarette smoking and subtypes of bladder cancer. Int J Cancer 2012;130:896-901.

22. Reznikoff CA, Sarkar S, Jülicher KP, Burger MS, Puthenveettil JA, Jarrard DF, et al. Genetic alterations and biological pathways in human bladder cancer pathogenesis. Urol Oncol 2000;5:191-203.

23. Silverman DT, Alguacil J, Rothman N, Real FX, Garcia-Closas M, Cantor KP, et al. Does increased urination frequency protect against bladder cancer? Int J Cancer 2008; 123:1644-8.

24. Chang $\mathrm{CH}$, Song JM. Effect of smoking on bladder cancer as a single risk factor. Korean J Urol 2004;45:1292-5.

25. Zeegers MP, Kellen E, Buntinx F, van den Brandt PA. The association between smoking, beverage consumption, diet and bladder cancer: a systematic literature review. World J Urol 2004;21:392-401.

26. Sylvester RJ, van der Meijden AP, Oosterlinck W, Witjes JA, Bouffioux C, Denis L, et al. Predicting recurrence and progression in individual patients with stage Ta T1 bladder cancer using EORTC risk tables: a combined analysis of 2596 patients from seven EORTC trials. Eur Urol 2006;49:466-77.

27. Sylvester RJ, Oosterlinck W, van der Meijden AP. A single immediate postoperative instillation of chemotherapy decreases the risk of recurrence in patients with stage Ta T1 bladder cancer: a meta-analysis of published results of randomized clinical trials. J Urol 2004;171(6 Pt 1):2186-90.

28. Sopori M. Effects of cigarette smoke on the immune system. 
Nat Rev Immunol 2002;2:372-7.

29. Sfakianos JP, Shariat SF, Favaretto RL, Rioja J, Herr HW. Impact of smoking on outcomes after intravesical bacillus Calmette-Guérin therapy for urothelial carcinoma not invading muscle of the bladder. BJU Int 2011;108:526-30.
30. Wang LC, Xylinas E, Kent MT, Kluth LA, Rink M, Jamzadeh A, et al. Combining smoking information and molecular markers improves prognostication in patients with urothelial carcinoma of the bladder. Urol Oncol 2014;32:433-40. 